Conclusion Patients with STDs are at risk for HCV infection and should be tested for HCV serology during their work-up.

\section{P3.164 HIGH RISK SEX BEHAVIOURS AMONG DRUG-USING REFUGEES: IMPLICATIONS FOR TREATMENT}

doi:10.1136/sextrans-2013-051184.0622

'Z Alam Mehrjerdi, ${ }^{2} \mathrm{~A}$ Hosseinzadeh, ${ }^{3} \mathrm{~N}$ Mansoori, ${ }^{2} \mathrm{~A}$ Deylamizadeh. ${ }^{1} /$ ranian National Center for Addiction Studies (INCAS), Tehran University of Medical Sciences, Tehran, Iran; ${ }^{2}$ Division of Research on Drug Use and Dependence, Rebirth Society (NGO), Tehran, Iran; ${ }^{3}$ Family Research Institue, Shahid Beheshti University, Tehran, Iran

Background Iran has been hosting Afghan refugees since the late 1970s. Yet, little is known about drug use and its relationships with high risk sex behaviours among this group. The present study describes the implemented harm reduction services and the correlates of high risk sex behaviours among the clients.

Methods In 2009, a four-month drug-related harm reduction programme was launched by Rebirth Society (NGO) with collaboration of UNHCR to implement harm reduction services for socially marginalised drug-using Afghan refugees in two Afghan-populated areas in Tehran. A drop in centre and a shelter were allocated to the project. A group of 10 doctors, psychologists and social workers were well trained to implement the services. Before starting the project, 6 Afghan outreach street workers informed resident Afghans in the areas about the services for 2 months with collaborations of some organisations and individuals such as the municipality, and Afghan volunteers.

Results From 1 September to 31 December 2009, 122 clients (121 men and 1 woman) with mean age $30.5(\mathrm{SD}=8$.) years referred for receiving treatment. 98.4\% were opioid users. 21 clients received methadone maintenance therapy. 14 clients received needle and syringe services. 21 received methadone detoxification. 50 clients received VCT counselling and serologic testing for viral infections. $41 \%$ had recently practised high risk sex behaviours. Recent high risk sex behaviours were associated with lack of current access to condom (OR 1.8, 95\% CI 1.1-7.6), low level of knowledge on safe sex (OR 1.8, 95\% CI 0.75-2.6), opioid use before sex (OR 1.1, 95\% CI $0.23-2.6)$ and duration of more than 5 years of dependence on drug use (or $1.28,95 \%$ CI 1-2.3).

Conclusion Providing free condoms and training in safe sex could decrease the rate of practising high risk behaviours among socially marginalised drug-using groups such as Afghans. Further studies are suggested.

\section{P3.165 ESTABLISHING SECOND GENERATION HIV/STI- SURVEILLANCE FOR MIGRANTS FROM SUB-SAHARAN AFRICA IN GERMANY - A PARTICIPATORY PROCESS}

doi:10.1136/sextrans-2013-051184.0623

${ }^{1} \mathrm{C}$ Santos-Hövener, ${ }^{1} \mathrm{O}$ Hamouda, ${ }^{1} \mathrm{C}$ Koschollek, ${ }^{\top} \mathrm{T}$ Charles, ${ }^{2} \mathrm{~T}$ Gangarova, ${ }^{1} \mathbf{U}$ Marcus ${ }^{1}$ Robert Koch-Institute, Berlin, Germany; ${ }^{2}$ Deutsche AIDS-Hilfe, Berlin, Germany

Background Migrants from sub-Saharan Africa (MisSA) are a relevant sub-group for HIV-transmission in Germany. $10-15 \%$ of all newly diagnosed cases are MisSA, and approximately one third acquired HIV in Germany. Diagnosis is often at a late clinical stage of HIV-infection, potentially due to barriers to HIV-testing or health care in general. There is limited information on prevalence of STIs and on knowledge, attitudes, behaviours and practises (KABP) regarding sexual health. To gain a deeper understanding of MisSA's HIV/STI-prevention needs a research process was initiated.

Methods An expert meeting took place to define specific research needs as well as a research approach. Experts were defined as persons working in HIV/STI-prevention with MisSA, key-persons from MisSA-communities and HIV/STI-researchers. A working group was established to draught a potential study design for a KABP-survey with MisSA. Recommendations of the working group were appraised by four focus groups with MisSA in different cities. Results The following guidelines for the research process were established:

- The research process will be participatory and MisSA have to be involved in all stages.

- All decisions will be evaluated by community members and an advisory board.

- The MisSA-community should benefit from the research.

The suggested study design was a multi-centre KABP-study on sexual health. Participants will be recruited by trained peer researchers. Optional HIV/STI-testing will be offered to participants. Questionnaires will be developed in a participatory approach and be available in multiple languages depending on the respective population of MisSA. Focus group results generally supported the suggested research design. A detailed analysis of focus group discussions is still ongoing.

Conclusion To conduct HIV/STI-research that is meaningful to MisSA, it is crucial to involve community partners in the research process. This will help to address the specific needs of MisSA and also assure a better reception of the study within the community.

\section{P3.166 LABOUR MIGRATION AND THE RISK OF INFECTION WITH STIS AND HIV AMONG WOMEN - WIVES OF MIGRANTS FROM TAJIKISTAN}

doi:10.1136/sextrans-2013-051184.0624

\section{A Karobekova. Tajik State Medical University, Душанбе, Tajikistan}

It is proved that labour migration contributes to the spread of STIs and HIV in the migrants' original places of residence. Due to geographical mobility and separation from their intimate partners for long period, migrants are at high risk of infection with variety of sexually transmitted infections (STIs), including HIV/AIDS.

Purpose The relationship between migration of men and the risk of infection with STIs and HIV among wives of migrants stayed back home.

Methods In order to process the data 1264 women of childbearing age from 18 to 45 years old were questioned in Dushanbe and DRS using multivariate statistic methods. Moreover, among the total number of women participating in survey, the number of female migrants was approximately equal to the number of wives of men who are not migrants. For modelling of static models both personal complaints about STI symptoms and reported cases of infection were used.

Results It was found out that under the same conditions, the wives of migrants complained of symptoms of STIs more often $(67.3 \%)$ than wives of non-migrants (31.3). In addition, there were more cases of HIV infection in this group. Risk factors as cervical ectopy (target cells facilitates survival of HIV in mucosa) is more commonly met with wives of migrants than wives of non-migrants. Conclusion These results illustrate not only the increased risk of STIs and HIV associated with labour migration, but also show the seriousness of the situation of migrants' wives who stay home with their children. Studies have shown that women should be better informed, to have possibility to resist development of epidemic.

\section{P3.167 YOUNG COMMERCIAL SEX WORKERS ARE AT HIGHER RISK OF SEXUALLY TRANSMITTED INFECTIONS, THE NETHERLANDS, 2006-2011}

doi:10.1136/sextrans-2013-051184.0625

${ }^{1,2}$ N Fournet, ${ }^{1} \mathrm{~F} D \mathrm{H}$ Koedijk, ${ }^{3} \mathrm{~A}$ P van Leeuwen, ${ }^{3} \mathrm{M} S$ van Rooijen, ' $\mathrm{S} J \mathrm{~J}$ Hahné, ${ }^{1,4} \mathrm{M}$ A B van der Sande, ${ }^{3} \mathrm{M}$ G van Veen, ${ }^{5} \mathrm{On}$ behalf of the Dutch STI clinics. 'National Institute of Public Health and the Environment, Bilthoven, The Netherlands; ' $E$ European Programme for Intervention Epidemiology Training (EPIET), European Centre for Disease 